\title{
Densidades de palha e condições de luminosidade na germinação de sementes de Euhphorbia heterophylla
}

\section{Densities straw and luminosity conditions on seed germination on seed germination of Euhphorbia heterophylla}

\author{
Renata Pereira Marques ${ }^{1}$; Dagoberto Martins ${ }^{2}$; \\ Saulo Ítalo de Almeida Costa ${ }^{3}$; Hermeson dos Santos Vitorino ${ }^{3}$
}

\begin{abstract}
Resumo
Estudou-se a influência da densidade de palha de cana-de-açúcar e condições de luminosidade sobre a germinação de sementes de Euphorbia heterophylla em condições controladas. O delineamento experimental foi inteiramente casualizado, com quatro repetições de 50 sementes, e os tratamentos foram dispostos no esquema fatorial $6 \times 5$, sendo seis quantidades de palha de cana-de-açúcar $(0,8$, 10, 12, 14 e $16 \mathrm{t} \mathrm{ha}^{-1}$ ) e cinco 5 tipos de luz (luz constante, escuro constante, alternância luz-escuro, vermelho curto e vermelho distante). As sementes foram colocadas para germinar em caixas plásticas do tipo gerbox e cobertas por camadas de palha sobrepostas e mantidas em câmaras de germinação. As avaliações de germinação foram diárias, computando-se as plântulas normais, quando apresentavam protusão radicular visível e calculado o índice de velocidade de germinação (IVG). O aumento das diferentes densidades de palha e diferentes comprimentos de onda proporcionaram germinação de 83 a $97 \%$ e IVG entre 9,85 a 15,36. As diferentes densidades de palha e comprimentos de onda não suprimiram a germinação de sementes de E. heterophylla, sendo a espécie insensível à luz. Assim sendo, a presença de palha em sistema de cana-crua não pode ser considerada ferramenta potencial para controle dessa espécie.
\end{abstract}

Palavras-chave: Leiteiro, cana-crua, plântulas, vermelho curto, vermelho distante

\begin{abstract}
It was studied the influence of sugarcane straw density and light conditions on the germination of seeds of Euphorbia heterophylla under controlled conditions. The experimental design was completely randomized design with four replications of 50 seeds, and the treatments were arranged in a $6 \times 5$ factorial, with six amount of sugarcane straw $\left(0,8,10,12,14\right.$ and $\left.16 \mathrm{tha}^{-1}\right)$ and 5 types of light (constant light, constant darkness, alternating light and dark, short red and far red). The seeds were germinated in plastic type boxes covered byoverlapping layers of straw and kept in germination. Assessments of germination were daily computing the normal seedlings, when they presented protusion roots visible and calculated the germination speed index (IGS). It was observed that the increase of different densities of straw and different wave lengths provided germination ranged from 83 to $97 \%$ and IGS between 9.85 to 15.36 . The different densities of straw and wavelength did not suppress the germination of $E$. heterophylla. Therefore, the species was insensitive to light, so the presence of raw sugarcane system can't be considered a potential tool for controlling this species.
\end{abstract}

Key words: Wild poinsettia, raw sugarcane, seedlings, short red, far red

\footnotetext{
1 Engenheira Agrônoma-Doutora em Produção Vegetal, Faculdade de Ciências Agronômicas/FCA/UNESP. Departamento de Produção Vegetal, Botucatu, SP. E-mail: renatapm_84@hotmail.com;

2 Engenheiro Agrônomo, Prof. Dr. Assistente da Faculdade de Ciências Agronômicas/FCA/UNESP. Departamento de Produção Vegetal, Botucatu, SP. E-mail: dmartins@fca.unesp.br

3 Engenheiro Agrônomo-Doutorandos em Produção Vegetal, Faculdade de Ciências Agronômicas/FCA/UNESP. Departamento de Produção Vegetal, Botucatu, SP.E-mail: sauloagro@gmail.com; vitorinohermeson@gmail.com

Autor para correspondência
} 


\section{Introdução}

Nos últimos anos, o processo de colheita da canade-açúcar vem se modificando da tradicional queima do canavial para a colheita da cana-crua, seja por imposições da legislação ou conscientização ambiental e também por pressões da sociedade. Mudanças da flora infestante têm sido observadas em áreas cultivadas com a cana-crua em consequência do favorecimento de espécies com maior capacidade de germinação sob espessa cobertura de palha, em comparação com outras que têm a germinação impedida por ação física ou alelopática da palhada (FERREIRA et al., 2010).

O conhecimento da biologia e o entendimento de como a germinação e emergência das plantas daninhas respondem ao sistema de produção agrícola são de grande importância para determinação da capacidade de adaptação e do potencial de infestação, podendo conduzir ao planejamento de medidas mais efetivas de controle (DIAS FILHO, 1996).

A avaliação das necessidades de controle das plantas daninhas é em função da taxa de emergência das espécies presentes no banco de sementes do solo e deve ser estabelecida para cada sistema de produção da cultura implantada (VOLL et al., 2001). A palha existente no sistema de cana-crua mantida sobre o solo pode constituir barreiras efetivas à germinação das plantas daninhas pelos processos: físico (fotoblásticas positivas), biológico (microorganismos deterioradores) e químico (alelopatia, alterações carbono/nitrogênio) sendo possíveis interações entre esses processos.

Segundo Pitelli e Durigan (2001), o efeito físico não se restringe apenas ao impedimento da passagem quantitativa e qualitativa da radiação solar, mas também a amenização da amplitude de variação térmica e da variação da umidade na camada superficial do solo.

No que se refere ao impedimento à germinação de sementes sob presença de palha, pela ausência parcial ou total de luminosidade, as áreas com produção de cana-crua podem contribuir para o controle de grandes infestações de certas espécies. Esse efeito foi verificado para sementes das espécies Bidens pilosa L. (FENNER, 1980).

Quando as sementes encontram-se no solo abaixo do dossel das culturas, a radiação solar é filtrada pelas folhas, permitindo menor passagem da radiação vermelho curto em relação ao vermelho distante. A quantidade de palha em uma área agrícola pode definir o comprimento de onda que chega até o banco de sementes. O aumento do componente vermelho curto da luz filtrada através do dossel tem um forte efeito promotor da germinação de sementes, enquanto o aumento do componente vermelho distante tem efeito inibitório à germinação da maioria das espécies.

Euphorbia heterophylla L., conhecida popularmente por leiteiro ou amendoim-bravo, é uma espécie de difícil controle e comum em áreas de produção de cana-crua. Segundo Wilson (1981) é tolerante à maioria dos herbicidas utilizados no controle às folhas largas. Assim sendo, o bloqueio da germinação das sementes de E. heterophylla pode representar um mecanismo de controle desta espécie e alguns estudos com esta abordagem foram realizados (GUSMAN; MUCILLO; PIRES, 1990).

\section{Como algumas características fisiológicas} das sementes de E. heterophylla ainda não são completamente conhecidas e pela importância da espécie em áreas de produção de cana-crua no Brasil, objetivou-se neste trabalho elucidar os efeitos das diferentes densidades de palha de cana-de-açúcar, bem como a influência da condição de luminosidade que chega ao banco de sementes sobre a germinação e índice de velocidade de germinação dessa espécie.

\section{Material e Métodos}

O experimento foi desenvolvido no Núcleo de Pesquisas Avançadas em Matologia (NUPAM), pertencente ao Departamento de Produção Vegetal da Faculdade de Ciências Agronômicas, UNESP, Botucatu-SP, para o qual utilizou-se sementes 
da espécie infestante E. heterophylla (leiteiro ou amendoim-bravo).

O delineamento experimental foi inteiramente casualizado, com quatro repetições de 50 sementes, com os tratamentos dispostos no esquema fatorial $6 \times 5$, sendo seis quantidades de palha de cana-deaçúcar $(0,8,10,12,14$ e 16 tha-1) e cinco 5 condições de luz (luz constante, escuro constante, alternância de luz-escuro, vermelho curto e vermelho distante).

As sementes foram colocadas para germinar em caixas plásticas do tipo gerbox sobre duas folhas de papel germitest e umedecidas com água destilada, com volume equivalente a 2,5 vezes a massa do papel seco. Posteriormente, as caixas foram colocadas em câmaras de germinação do tipo BOD reguladas para temperaturas constantes de $30 \pm 1^{\circ} \mathrm{C}$.

As diferentes densidades de palha foram obtidas utilizando folhas coletadas de plantas de cana-deaçúcar, da variedade SP80-1842 desidratadas e cortadas na dimensão do gerbox e encaixadas sobre as sementes.

No tratamento luz constante (LC) utilizouse gerbox transparente sem palha; para o escuro constante (EC) utilizou-se gerbox preto; para o tratamento luz-escuro (LE) usou a alternância de 16 horas de luz para 8 horas de escuro, controlada pela regulagem do germinador tipo BOD; para o vermelho curto (VC) utilizou-se duas folhas de papel celofane vermelho e para o vermelho distante (VD) utilizou duas folhas de papel celofane azul e duas folhas vermelhas envolvendo o gerbox.

Avaliou-se a germinação e o Índice de Velocidade de Germinação (IVG). Foram consideradas germinadas as sementes que apresentaram a protusão radicular visível. A cada contagem diária as sementes germinadas foram removidas. O teste teve duração de 10 dias, quando $90 \%$ dos tratamentos estavam com germinação estabilizada. A contagem das sementes foi realizada sob luz verde de segurança.

O índice de velocidade de germinação foi avaliado em conjunto com o teste de germinação. Ao final do teste, com os dados diários do número de plântulas normais, calculou-se o índice de velocidade de germinação, empregando-se a equação proposta por Maguire (1962), ou seja: IVG $=\mathrm{G}_{1} / \mathrm{N}_{1}+\mathrm{G}_{2} / \mathrm{N}_{2}+\ldots+\mathrm{G}_{\mathrm{n}} / \mathrm{N}_{\mathrm{n}}$ em que:

$\mathrm{G}_{1 \ldots \mathrm{n}}=$ número de plântulas normais computadas nas contagens; $\mathrm{e}_{1 \ldots \mathrm{n}}=$ número de dias da semeadura à primeira, segunda ... enésima avaliação.

Os dados obtidos foram submetidos à análise de variância e as interações significativas desdobradas. As médias dos tratamentos foram comparadas pelo teste de Tukey a $5 \%$ de probabilidade e ajustadas por meio de equações de regressão das variáveis, em função das densidades de palha.

\section{Resultados e Discussão}

O tratamento alternância luz-escuro apresentou os maiores valores para o IVG e porcentagem de germinação, sendo que para o IVG o este tratamento diferenciou dos demais, os quais não diferenciaram entre si (Tabela 1).

Para porcentagem de germinação o tratamento luz-escuro também foi o que apresentou maiores valores, enquanto o os tratamentos luz constante e escuro constante se mantiveram com valores intermediários com relação aos demais. Ressaltase que em todos os tratamentos a germinação teve início no segundo dias após a semeadura. 
Tabela 1. Porcentagem de germinação de sementes de Euphorbia heterophylla sob diferentes condições de densidade de palha e de luminosidade. Botucatu-SP, 2010.

\begin{tabular}{|c|c|c|}
\hline Densidade de Palha (t ha' $)$ & IVG & $\begin{array}{l}\text { Germinação } \\
(\%)\end{array}$ \\
\hline 0 & 11,10 & 77 \\
\hline 8 & 12,90 & 85 \\
\hline 10 & 12,25 & 84 \\
\hline 12 & 13,25 & 85 \\
\hline 14 & 13,00 & 85 \\
\hline 16 & 13,10 & 85 \\
\hline Regressão & -------- & -------- \\
\hline \multicolumn{3}{|l|}{ Condição de Luz } \\
\hline Vermelho Curto $\quad$ (VC) & $11,63 \mathrm{~b}$ & $81 \mathrm{~b}$ \\
\hline Vermelho Distante (VD) & $12,50 \mathrm{~b}$ & $82 \mathrm{~b}$ \\
\hline Escuro Constante $\quad$ (EC) & $12,38 \mathrm{~b}$ & $83 \mathrm{ab}$ \\
\hline Luz Constante $\quad$ (LC) & $12,25 \mathrm{~b}$ & $84 \mathrm{ab}$ \\
\hline Alternância Luz-Escuro (LE) & $14,25 \mathrm{a}$ & $88 \mathrm{a}$ \\
\hline Tratamento x Densidade & $5,80 * *$ & $6,03 * *$ \\
\hline d.m.s & 1,21 & 5,33 \\
\hline C.V. $(\%)$ & 11,96 & 7,92 \\
\hline
\end{tabular}

**significativo a $1 \%$ de probabilidade; * significativo a $5 \%$ de probabilidade.

Médias seguidas de mesma letra, na coluna, não diferem pelo teste Tukey a $5 \%$ de probabilidade.

Fonte: Elaboração dos autores.

Na Figura 1 pode-se observar a porcentagem de germinação de E. heterophylla em função da densidade de palha. Os tratamentos vermelho curto, escuro constante e o de alternância de luzescuro apresentaram diferenças significativas com a variação da densidade da palha; de modo que nos tratamentos vermelho curto e alternância de luzescuro a porcentagem de germinação apresentou comportamento linear. No entanto, observou-se que para o tratamento vermelho curto houve redução da porcentagem de germinação com o aumento da quantidade de palha, enquanto para o tratamento luzescuro a germinação foi diretamente proporcional ao aumento na densidade de palha. Para o tratamento escuro constante o pico de germinação ocorreu com a densidade de palha $12 \mathrm{tha}^{-1}$.

Martins et al. (1999) também verificaram que plântulas de E. heterophylla são capazes de emergir em camadas de palha de cana-de-açúcar até 15 tha1. De acordo com Monquero et al. (2007) somente a partir de $20 \mathrm{t} \mathrm{ha}^{-1}$ de palha de cana-de-açúcar pode ocorrer a supressão a germinação da espécie.
Contudo, as plantas de E. heterophylla (leiteiro) também tiveram sua emergência e desenvolvimento observados em áreas com e sem palha de canade-açúcar confirmando que sementes de $E$. heterophylla são insensíveis a luz. Bannon, Baker e Rogers (1978) acrescentam, ainda, que dependendo do regime de temperatura a luz pode ser promotora, inibidora ou não ter efeito sobre a germinação.

Na Figura 2 e na Tabela 1, observa-se o índice de velocidade de germinação (IVG) de sementes de E. heterophylla em que os tratamentos vermelho curto, escuro constante e alternância de luzescuro apresentaram diferenças significativas com a variação da densidade da palha, sendo que os tratamentos vermelho distante e alternância luz-escuro apresentaram comportamento linear, aumentando o IVG conforme aumentava-se a densidade de palha, sendo que o maior índice para o tratamento vermelho distante foi sob palha de $10 \mathrm{t}$ $\mathrm{ha}^{-1}$, enquanto para o tratamento luz-escuro o pico de ocorreu sob palha de $16 \mathrm{tha}^{-1}$. O tratamento escuro constante apresentou comportamento quadrático 
com o maior índice observado na densidade de palha de $12 \mathrm{t} \mathrm{ha}^{-1}$. Segundo Ferreira et al. (2010) para melhor efeito da cobertura morta sobre as plantas daninhas, três fatores são primordiais: a quantidade $\left(\mathrm{t} \mathrm{ha} \mathrm{a}^{-1}\right)$, a densidade e a uniformidade de distribuição de palha da cana-de-açúcar no solo.

Figura 1. Densidade e palha e luminosidade sobre a Germinação de sementes Euphorbia heterophylla. Botucatu-SP, 2010.

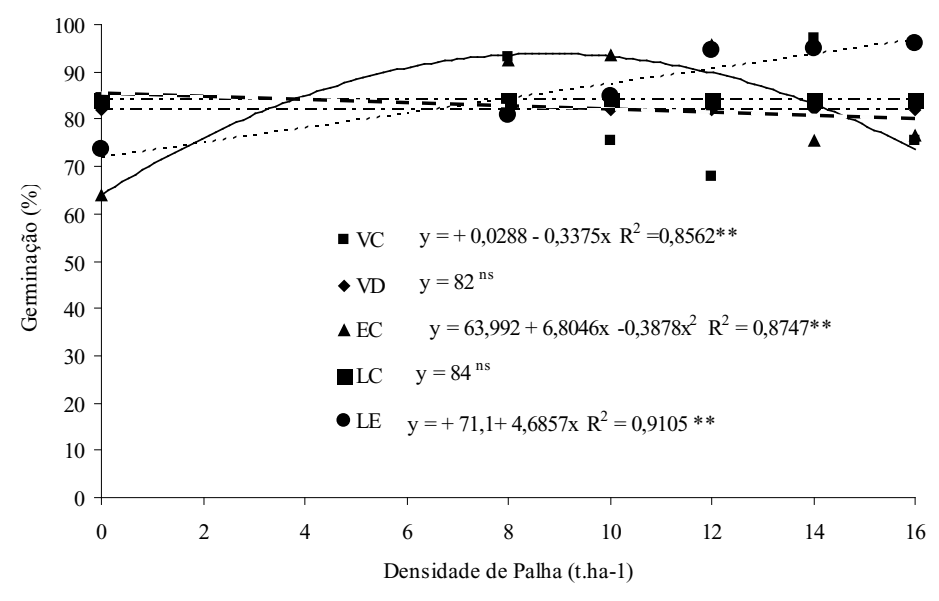

$\left({ }^{* *}\right)$ :significativo a $1 \%$ de probabilidade; $\left({ }^{*}\right)$ :significativo a $5 \%$ de probabilidade; $\left({ }^{\mathrm{ns}}\right)$ : não-significativo.

Fonte: Elaboração dos autores.

Figura 2. Densidade de palha e luminosidade sobre o Índice de Velocidade de Germinação de sementes Euphorbia heterophylla. Botucatu-SP, 2010.

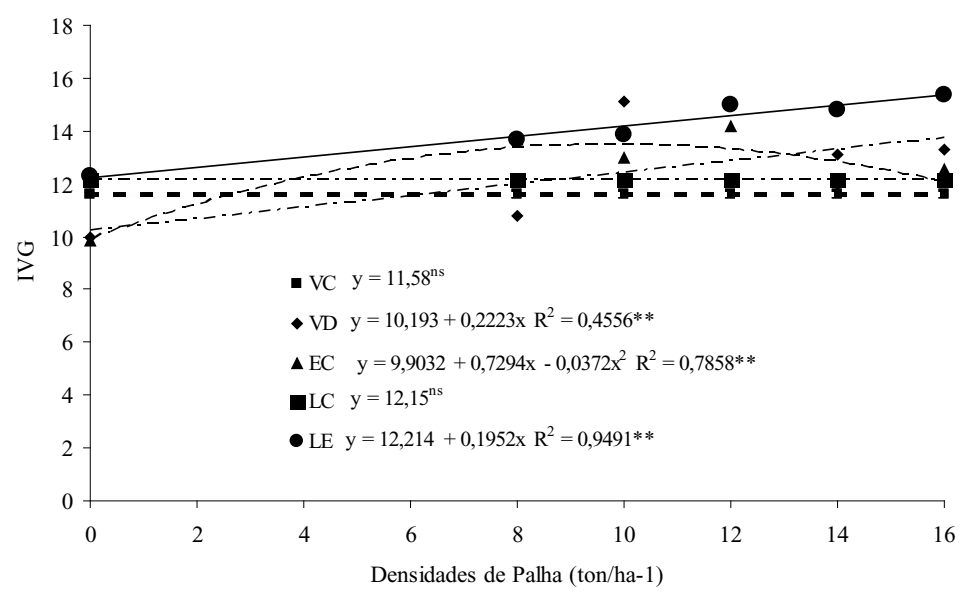

$\left({ }^{* *}\right)$ : significativo a $1 \%$ de probabilidade; $\left({ }^{*}\right)$ : significativo a $5 \%$ de probabilidade; $\left({ }^{\text {ns)}): ~ n a ̃ o-s i g n i f i c a t i v o . ~}\right.$

Fonte: Elaboração dos autores.

A luz é um dos fatores essenciais para a outras por condições fisiológicas. Arévalo (1998) germinação; contudo, existem espécies que observou que a alteração na quantidade de palha germinam também na ausência desta, algumas por sobre o solo de 1-5 para 5-15 $\mathrm{t}$ ha $^{-1}$ modificou as adaptação das condições adversas do ambiente, espécies infestantes da área. No entanto, ao alterar 
para mais que 15 tha $^{-1}$ de palhada, surgiram diferentes espécies que até então não haviam aparecido nas menores quantidades de palha como é o caso de $E$. heterophylla. Esse fato pode ser explicado em razão de que determinadas espécies daninhas só emergem com menor quantidade de luz disponível, ou seja, são chamadas de plantas fotoblásticas negativas (PROCÓPIO et al., 2003).

Segundo Klein e Felippe (1991), a espécie E. heterophylla pode apresentar fotoblastismo positivo após ser armazenada por um período de sete meses, porém o que se observou neste estudo foi que tal espécie apresentou germinação indiferente quanto à preferência pela luz, indicando que o tempo de armazenamento pode ter influenciado o fotoblastismo, que, no caso deste estudo, foi de três meses.

\section{Conclusão}

Conforme os dados não pode-se considerar a presença de palha existente no sistema de cana-crua como possibilidade de controle de E. heterophylla, uma vez que indicam que esta espécie apresentou Índice de Velocidade de Germinação e porcentagem de germinação elevados em ambientes com diferentes luminosidades. Quantidades maiores de palha podem suprimir a germinação dessa espécie, no entanto, pode também prejudicar a eficácia de herbicidas pela dificuldade de transpor a palha, fazse necessário, portanto, outras estratégias de controle de E. heterophylla que não somente o químico.

\section{Referências}

ARÉVALO, R. A. Manejo de plantas daninhas em áreas de colheita de cana-crua. STAB Açúcar, Álcool Subprodutos, Piracicaba, v. 16, n. 4, p. 26-28, 1998.

BANNON, J. S.; BAKER, J. B.; ROGERS, R. L. Germination of wild poinsettia (Euphorbia heterophylla). Weed Science, Champaign, v. 26, n. 3, p. 221-225, 1978.

DIAS FILHO, M. B. Germination and emergence of Stachytarpheta cayennensis and Ipomoea asarifolia. Planta Daninha, Viçosa, MG, v. 14, n. 2, p. 118-126, 1996.
FENNER, M. Germination tests on thirty-two east African weed species. Weed Research, Oxford, v. 20, n. 3, p. 135-138, 1980.

FERREIRA, E. A; PROCÓPIO, S. O.; GALON, L.; FRANCA, A. C.; CONCENÇO, G.; SILVA, A. A.; ASPIAZU, I.; SILVA, A. F.; TIRONI, S. P.; ROCHA, P. R. R. Manejo de plantas daninhas em cana-crua. Planta Daninha, Viçosa, MG, v. 28, n. 4, p. 915-925, 2010.

GUSMAN, A. B.; MUCILLO, G.; PIRES, M. H. Efeito do citronelol sobre a germinação e desenvolvimento do amendoim-bravo (Euphorbia heterophylla L.). Semina: Ciências Agrárias, Londrina, v. 11, n. 1, p. 20-24, 1990.

KLEIN, A.; FELIPPE, G. M. Efeito da luz na germinação de sementes de ervas invasoras. Pesquisa Agropecuária Brasileira, Brasília, v. 26, n. 7, p. 955-966, 1991.

MAGUIRE, J. D. Speed of germination-aid in selection and evaluation for seedling emergence and vigor. Crop Science, Madison, v. 2, n. 1, p. 176-177, 1962.

MARTINS, D. D.; VELINI, E. D.; MARTINS, C. C.; SOUZA, L. S. Emergência em campo de dicotiledôneas infestantes em solo coberto com palha de cana-de-açúcar. Planta Daninha, Viçosa, MG, v. 17, n. 1, p. 151-161, 1999.

MONQUERO, P. A.; AMARAL, L. R.; SILVA, A. C.; SILVA, P. V.; BINHA, D. P. Eficácia de herbicidas em diferentes quantidades de palha de cana-de-açúcar no controle de Euphorbia heterophylla. Planta Daninha, Viçosa, MG, v. 25, n. 3, p. 613-619, 2007.

PITELLI, R. A.; DURIGAN, J. C. Ecologia das plantas daninhas no sistema plantio direto. In: ROSSELLO, R. D. Siembra directa en el cono sur. Montevideo: PROCISUR, 2001. p. 203-210.

PROCÓPIO, S. O.; SILVA, A. A.; VARGAS, L.; FERREIRA, F. A. Manejo de plantas daninhas na cultura da cana-de-açúcar. Viçosa, MG: Universidade Federal de Viçosa, 2003. 150 p.

VOLL, E.; TORRES, E.; BRICHENTI, A. M.; GAZZIERO, D. L. P. Dinâmica de um banco de sementes de plantas daninhas sob diferentes manejos do solo. Planta Daninha, Viçosa, MG, v. 19, n. 2, p. 171-178, 2001.

WILSON, A. K. Euphorbia heterophylla: a review of distribution, importance and control. Tropical Pest. Management, London, v. 27, n. 1, p. 32-38, 1981. 